\title{
Anxiety disorders in children with high intellectual potential
}

\author{
Solenn Kermarrec, Laurie Attinger, Jacques-Henri Guignard and Sylvie Tordjman
}

\section{Background}

Several studies have reported anxiety disorders in children with high intellectual potential (HIP). However, there are discrepant results possibly as a result of methodological biases (different/ absent definitions of HIP, small sample sizes, non-validated/ adapted/specific tools for assessing anxiety and a single observational source).

\section{Aims}

To examine more thoroughly the relationships between HIP and anxiety in large samples of children using clear definitions of HIP, different observational sources and specific assessments of anxiety.

\section{Method}

Children with HIP $(n=211$, total IQ $\geq 130)$ were compared with children without HIP $(n=397$, total IQ <130) for anxiety using different observational sources (child psychiatric diagnosis, parental evaluation and child's self-evaluation). Intellectual functioning was assessed using the Wechsler Intelligence Scale.

\section{Results}

There were significantly more children with HIP who had anxiety disorders than children without HIP based on the child psychiatric diagnosis. Moreover, based on the child's self-evaluation, children with a high Verbal Comprehension Index $(\mathrm{VCl} \geq 130)$ were significantly more anxious than children with a $\mathrm{VCl}<130$, whereas children with a high Perceptual Reasoning Index $(P R I \geq 130)$ were significantly less anxious than children with a
$P R I<130$. Finally, there was no significant relationship between levels of intellectual functioning and anxiety according to parental observation.

\section{Conclusions}

The results highlight the importance of using multiple observational sources and conducting analyses on different dimensions of intellectual functioning (such as VCI and PRI), rather than only on the composite total IQ score. High verbal potential might be a factor of vulnerability for anxiety, whereas high perceptual reasoning might be a protective factor. Further studies are necessary to understand better the mechanisms underlying these results.

\section{Keywords}

High intellectual potential; gifted; cognitive profile; anxiety; children.

\section{Copyright and usage}

(c) Royal College of Psychiatrists 2020. This is an Open Access article, distributed under the terms of the Creative commons Attribution-NonCommercial-NoDerivatives licence (http://creativecommons.org/licenses/by-nc-nd/4.0/), which permits noncommercial re-use, distribution, and reproduction in any medium, provided the original work is unaltered and is properly cited. The written permission of Cambridge University Press must be obtained for commercial re-use or in order to create a derivative work.
Many clinical and parental observations report anxiety in children with high intellectual potential (HIP). We provide a service for children with HIP with emotional, behavioural and/or school problems at the National Center for Assistance to children and adolescents with High Potential (CNAHP) created in a French hospital-university department of child and adolescent psychiatry to identify and provide adapted care to these HIP youths with difficulties. More precisely, out of the first 338 children and adolescents referred to the CNAHP, a high proportion displayed school problems (78\%), including school failure, and the following disorders according to ICD- $10^{1}$ and the DSM- $5^{2}$ diagnostic classifications: anxiety disorders $(40.5 \%)$, intellectual disabilities (6.8\%), conduct disorder (9.5\%), depressive disorders (8\%), personality disorders $(3.5 \%)$, attention-deficit hyperactivity disorder (3.5\%), obsessive-compulsive disorder (1.5\%) and other problems (26.6\% including, for example, family problems with sibling conflicts). ${ }^{3}$ Anxiety disorders are therefore the most frequent psychiatric disorders observed in this population. However, there have been relatively few studies of psychological and emotional disorders among children with HIP, and their results have been contradictory. Indeed, many studies on anxiety in children with HIP reported high levels of anxiety and the authors have suggested that high cognitive ability might be a vulnerability factor for psychiatric disorders. ${ }^{4,5}$ However, some authors have failed to observe any significant difference in anxiety levels between children with HIP and their peers without HIP. ${ }^{6-8}$ Finally, other authors have found that children with HIP were significantly less anxious than children of average intelligence, suggesting that children with HIP are better at coping with stressful situations and are somehow protected by their high cognitive abilities. ${ }^{9-13}$ It is noteworthy that the Martin et al meta-analysis highlighted lower levels of anxiety in individuals with HIP compared with individuals without HIP. ${ }^{14}$ It appears difficult to reach firm conclusions on the relationship between anxiety and HIP based on these contradictory results, which can be explained in part by methodological biases, such as different/absent definitions of HIP for the recruitment of participants to the studies, ${ }^{4,8,12}$ small sample sizes, ${ }^{4,7,8,15,16}$ non-validated/adapted/specific tools for assessing anxiety and a single observational source for the evaluation of anxiety. Indeed, anxiety was assessed using mostly child's self-report evaluation, ${ }^{6-8,10,11,12,15}$ but also parental observation only ${ }^{5,16}$ or psychiatric evaluation. ${ }^{13}$ There are also studies ${ }^{6}$ that did not compare individuals with HIP with individuals without HIP, raising questions therefore about the specificity of the results regarding high levels of intellectual functioning.

Given the discrepant results and methodological biases described above, the objective of the present study was to examine more thoroughly the relationships between high intellectual functioning and anxiety by comparing large samples of children with HIP and children without HIP, using clear definitions of HIP, with validated/adapted/specific assessment tools of anxiety in various and concomitant observational situations (parental evaluation, child psychiatric evaluation and child's self-report evaluation). 


\section{Method}

\section{Participants}

The sample consisted of 608 children (mean age: 10.6 years, s.d. $=$ 2.9, ranging from 6 to 16.1 years old, including 211 children with HIP (total IQ $\geq 130,175$ boys and 36 girls, mean age: 10.7 years, s.d. $=3.0$ ) and 397 children without HIP (total IQ $<130,333$ boys and 64 girls, mean age: 10.5 years, s.d. $=2.8)$. They were all referred to the CNAHP, which provides a global psychological evaluation based on several tools, including cognitive, conative and socioemotional assessments given their problems (intellectual disabilities with school difficulties, emotional and/or behavioural problems). In addition, children and adolescents living near the CNAHP $(1 \mathrm{~h}$ away maximum) are systematically referred to a child psychiatrist working in the CNAHP who becomes the medical referent in case of therapeutic follow-up after the psychological and psychiatric evaluation.

Written informed consent was obtained from all parents after explaining the study and its procedure to the parents and their children. The protocol was approved by the ethics committee of Rennes University Hospital.

\section{Cognitive and anxiety assessments Identification of HIP}

Children's intellectual functioning was assessed by a psychologist using the Wechsler Intelligence Scale (WISC)-IV ${ }^{17}$ validated for children and adolescents aged from 6 to 16 years, 11 months. The WISC-IV scale has been shown to have very good reliability and validity. ${ }^{17}$ Four composite scores were calculated based on ten subtests: the Verbal Comprehension Index (VCI), the Perceptual Reasoning Index (PRI), the Working Memory Index (WMI) and the Processing Speed Index (PSI). If a child had been already assessed using the WISC-IV less than 1 year ago, this child was not included in the study given that the reliability of the results from a new WISC-IV administration can be questioned.

\section{Evaluation of anxiety}

Anxiety was assessed according to three different observational sources: parents, child psychiatrist and child.

Parental evaluation. A parental questionnaire was used during a semi-structured phone interview (parental observation) conducted systematically for all parents by the same trained secretary when parents called to get an appointment for their child at the CNAHP. This interview includes questions about school, behavioural and/or emotional difficulties, such as anxiety problems, in order to check if the potential help provided by CNAHP is adapted to the parental request. Therefore, questions related to anxiety problems are asked consistently in the same way by the same professional for all parents.

Child psychiatric evaluation. The child psychiatric evaluation for ICD-10 and DSM-5 diagnostic criteria of anxiety disorders, based on psychiatric observation of the child or adolescent, provides a clinical psychiatric judgement. This psychiatric evaluation is performed only for children and adolescents living near the CNAHP and who could therefore benefit from regular therapeutic followup (as previously indicated in the Participants section).

Child's self-report evaluation. The Revised-Children's Manifest Anxiety Scale (R-CMAS) ${ }^{18}$ is a self-report inventory for children from 6 to 19 years old. The R-CMAS, subtitled 'what I think and feel', is used to assess the level and nature of anxiety in children and adolescents. The R-CMAS provides a total anxiety score based on 28 anxiety items grouped in three subscales: physiological anxiety, worry/oversensitivity and social concerns/concentration. The physiological anxiety subscale is related to somatic symptoms associated with anxiety (such as sleep latency problems, nausea, fatigue, etc.). The worry/oversensitivity subscale is related to obsessional worries associated with fears of being emotionally hurt or isolated. The social concerns/concentration subscale is associated particularly with school problems and is related to social fears leading to attention or concentration difficulties.

The R-CMAS has been validated and used in research studies to measure anxiety in children with and without HIP. ${ }^{10}$ Also, there are nine lie scale items corresponding to social desirability. When these lie scores are too high, the other R-CMAS scores cannot be interpreted. In the present study, if a child got a score above 70 on the R-CMAS lie subscale, this individual was not included in the study. A R-CMAS total score between 60 and 70 corresponds to moderate anxiety levels and a R-CMAS total score above 70 corresponds to severe anxiety levels.

Concerning the assessment procedure, the R-CMAS self-report inventory was completed by the child at the CNAHP in the presence of a psychologist, who was available to answer the child's possible questions. Indeed, it appears it is important that the child neither completes the R-CMAS at home in the presence of parents, who might influence the child's responses, nor in a room alone given the potential emotional content of certain questions.

\section{Statistical analyses}

The relationships between anxiety (parental observation or child psychiatric diagnosis) and intellectual functioning (WISC-IV total IQ score and WISC-IV indices) were studied using either $t$-tests or $\chi^{2}$-tests when the HIP group (IQ scores $\geq 130$ ) was compared with the non-HIP group (IQ scores <130). The relationships between the R-CMAS anxiety scores (child's self-report evaluation) and levels of intellectual functioning (WISC-IV total IQ score and WISC-IV indices) were studied using $t$-tests when the HIP group (IQ scores $\geq 130$ ) was compared with the non-HIP group (IQ scores $<130)$.

\section{Results}

\section{Descriptive analysis}

To specify further the intellectual characteristics of the participants, we provide here the details of the WISC-IV scores for all the participants and the HIP and non-HIP groups (Table 1). It is noteworthy that the VCI is particularly high in the whole sample and the non-HIP group, and is the highest index in the HIP group.

The child psychiatric evaluation was conducted for 324 out of 608 children given that, as explained in the Method section, only children living near the CNAHP area were systematically addressed to the child psychiatrist at the CNAHP for possible therapeutic follow-up. The parental evaluation and child's self-report evaluation were obtained from all parents and children $(n=608)$.

Based on psychiatric evaluation, anxiety disorders were observed in 162/324 (50\%) of children attending the CNAHP and included mainly generalised anxiety disorder (143/324, 44.1\%), but also phobic anxiety disorder $(14 / 324,4.3 \%)$ and separation anxiety disorder $(5 / 324,1.5 \%)$ according to DSM-5 and ICD-10 diagnostic criteria. Based on parental evaluation, the frequency of individuals with anxiety in the whole sample was $487 / 608$ (80.1\%).

Based on the child's self-report questionnaire (R-CMAS), anxiety was found in $145 / 608(23.8 \%)$ of children, and about two-thirds of them $(97 / 145,66.9 \%)$ displayed moderate anxiety 
Table 1 Descriptive analysis of Wechsler Intelligence Scale (WISC-IV) scores for the high intellectual potential (HIP) group $(n=211)$, the nonHIP group $(n=397)$ and all the participants $(n=608)$

\begin{tabular}{|c|c|c|c|c|c|c|}
\hline \multirow[b]{2}{*}{ WISC-IV } & \multicolumn{2}{|c|}{$\begin{array}{c}\text { All } \\
\text { participants } \\
\end{array}$} & \multicolumn{2}{|c|}{$\begin{array}{l}\text { Non-HIP } \\
\text { group }\end{array}$} & \multicolumn{2}{|c|}{ HIP group } \\
\hline & Mean & s.d. & Mean & s.d. & Mean & s.d. \\
\hline Verbal Comprehension Index & 132.0 & 15.7 & 126.6 & 15.1 & 142.2 & 11.1 \\
\hline Perceptual Reasoning Index & 117.3 & 15.3 & 111.1 & 13.5 & 128.9 & 11.1 \\
\hline Working Memory Index & 109.2 & 16.4 & 102.4 & 14.2 & 122.0 & 11.8 \\
\hline Perceptual Speed Index & 106.0 & 16.6 & 101.6 & 15.2 & 114.2 & 16.1 \\
\hline Total IQ score & 124.2 & 14.5 & 116.1 & 10.5 & 139.3 & 6.7 \\
\hline
\end{tabular}

(R-CMAS total score between 60 and 70) and a third of them (48/ $145,33.1 \%$ ) displayed severe anxiety (R-CMAS total score above a threshold of 70).

According to the children's self-report evaluations, the distribution in the whole sample $(n=608)$ of the R-CMAS total anxiety score and the three different R-CMAS subscales scores were as follows: mean $=51.63$ (s.d. $=12.87$ ) (total anxiety score); mean $=$ 51.83 (s.d. $=10.96)$ (physiological anxiety); mean $=49.67$ (s.d. $=$ 12.84) (worry/oversensitivity); mean $=52.92$ (s.d. =11.41) (social concerns/concentration).

\section{Relationships between intellectual functioning and anxiety according to the parental, child psychiatric or child evaluation}

The relationships between intellectual functioning and anxiety according to the child's self-evaluation, child psychiatric evaluation and parental evaluation are presented in Tables 2-4. There were no significant relationships between anxiety and intellectual functioning according to the child, child psychiatric or parental observational source when children were grouped with respect to the 130 cut-offs of intellectual giftedness for the WMI and PSI indices. Therefore, only total IQ, VCI and PRI levels are presented in Tables 2-4.

According to the child's self-report evaluation, when children were grouped with respect to the 130 cut-off of intellectual giftedness for the VCI index, the R-CMAS scores of total anxiety, physiological anxiety and worry/oversensitivity were significantly higher in the $\mathrm{VCI} \geq 130$ group compared with the $\mathrm{VCI}<130$ group (Table 2). Inversely, when children were grouped with respect to the 130 cut-off of intellectual giftedness for the PRI index, the R-CMAS scores of total anxiety and worry/oversensitivity were significantly lower in the PRI $\geq 130$ group compared with the $\mathrm{PRI}<130$ group (Table 2). Also, it is noteworthy that VCI and PRI were significantly and positively correlated $(r=0.45, P<0.05)$.

Based on the child psychiatrist's evaluation, there was a significant relationship between total IQ scores and anxiety disorders according to ICD-10 diagnostic criteria. However, no significant relationship was observed between psychiatric diagnosis of anxiety disorders and any of the four WISC-IV indices (VCI, PRI, WMI or PSI index). The results are also presented for the VCI and PRI indices to allow the comparison with the child's self-evaluation (Table 3).

Based on the parental observation of anxiety, no significant relationships were found between intellectual functioning (total IQ score or any of the four WISC-IV indices) and anxiety (Table 4). The results are also presented in Table 4 for the VCI and PRI indices to allow comparison with the child's self-evaluation.

Finally, there was no significant relationship between the results compared across the three observational sources (parental, child psychiatric and child evaluations).

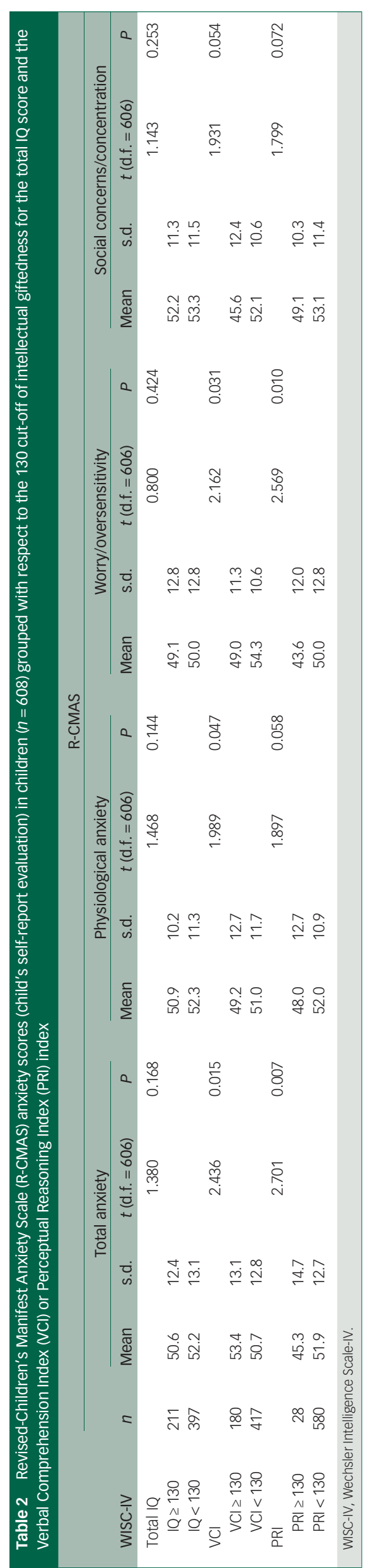


Table 3 Relationship in children $(n=324)$ between anxiety (child psychiatric evaluation according to ICD-10 and DSM- 5 criteria) and

intellectual functioning for total IQ score, Verbal Comprehension Index (VCI) and Perceptual Reasoning Index (PRI) ${ }^{\mathrm{a}}$

\begin{tabular}{|c|c|c|c|c|c|c|c|}
\hline \multirow[b]{3}{*}{ WISC-IV } & \multirow[b]{3}{*}{$n$} & \multicolumn{4}{|c|}{ Anxiety } & & \\
\hline & & \multicolumn{2}{|c|}{ Yes } & \multicolumn{2}{|c|}{ No } & \multicolumn{2}{|c|}{ Fisher exact test } \\
\hline & & $n$ & $\%$ & $n$ & $\%$ & $\chi^{2}(1)$ & $P$ \\
\hline \multicolumn{6}{|l|}{ Total IQ } & 3.83 & $<0.050$ \\
\hline $\mathrm{IQ} \geq 130$ & 119 & 68 & 57.1 & 51 & 42.9 & & \\
\hline $\mathrm{IQ}<130$ & 205 & 94 & 45.9 & 111 & 54.1 & & \\
\hline \multicolumn{6}{|l|}{$\mathrm{VCl}$} & 0.749 & 0.387 \\
\hline $\mathrm{VCl} \geq 130$ & 91 & 42 & 46.1 & 49 & 53.9 & & \\
\hline $\mathrm{VCl}<130$ & 233 & 120 & 51.5 & 113 & 48.5 & & \\
\hline \multicolumn{6}{|l|}{ PRI } & 0.559 & 0.455 \\
\hline$P R I \geq 130$ & 17 & 10 & 58.8 & 7 & 41.2 & & \\
\hline $\mathrm{PRI}<130$ & 307 & 152 & 49.5 & 155 & 50.5 & & \\
\hline \multicolumn{8}{|c|}{$\begin{array}{l}\text { a. The results are expressed as the frequency of children with anxiety or without anxiety } \\
\text { when children are grouped with respect to the } 130 \text { cut-off of intellectual giftedness for } \\
\text { total IQ score, VCI and PRI. } \\
\text { WISC-IV, Wechsler Intelligence Scale-IV. }\end{array}$} \\
\hline
\end{tabular}

\section{Discussion}

\section{Relationships between overall intellectual functioning and anxiety}

A significant relationship was found between children's overall intellectual functioning (total IQ) and anxiety disorders diagnosed by the child psychiatrist according to the ICD-10 and DSM-5 criteria. This result confirms the findings of certain studies described in the introductory section reporting high levels of anxiety among children with HIP who have difficulties. ${ }^{5,8}$ Children with HIP may exhibit anxiety because of their cognitive maturity and increased awareness leading to existential questions and associated anticipatory anxiety. Indeed, high overall intellectual functioning might lead to worries and therefore anxiety related to social preoccupations and questions about abstract concepts, not easily handled by some children given their young age and psychoaffective development. Inversely, anxiety corresponds to a state of hyperarousal with possible increased attention and alertness to environmental stimuli, which may contribute to high overall intellectual functioning.

There was no significant relationship between the children's overall level of intellectual functioning (total IQ) and anxiety, as assessed by either child's self-report evaluation (R-CMAS) or parental observation. It should be noted that anxiety was the most frequent psychological problem reported by parents (whole sample:

\begin{tabular}{|c|c|c|c|c|c|c|c|}
\hline \multirow[b]{3}{*}{ WISC-IV } & \multirow[b]{3}{*}{$n$} & \multicolumn{4}{|c|}{ Anxiety } & & \\
\hline & & \multicolumn{2}{|c|}{ Yes } & \multicolumn{2}{|c|}{ No } & \multicolumn{2}{|c|}{ Fisher exact test } \\
\hline & & $n$ & $\%$ & $n$ & $\%$ & $\chi^{2}(1)$ & $P$ \\
\hline Total IQ & & & & & & 3.83 & 0.819 \\
\hline $\mathrm{IQ} \geq 130$ & 211 & 170 & 80.7 & 41 & 19.3 & & \\
\hline $\mathrm{IQ}<130$ & 397 & 317 & 79.8 & 80 & 20.2 & & \\
\hline $\mathrm{VCl}$ & & & & & & 0.749 & 0.848 \\
\hline $\mathrm{VCl} \geq 130$ & 180 & 143 & 79.6 & 37 & 20.4 & & \\
\hline $\mathrm{VCl}<130$ & 417 & 335 & 80.3 & 82 & 19.7 & & \\
\hline PRI & & & & & & 0.559 & 0.091 \\
\hline$P R I \geq 130$ & 28 & 19 & 66.7 & 9 & 33.3 & & \\
\hline $\mathrm{PRI}<130$ & 580 & 469 & 80.8 & 111 & 19.2 & & \\
\hline
\end{tabular}

a. The results are expressed as the frequency of children with anxiety or without anxiety when children are grouped with respect to the 130 cut-off of intellectual giftedness fo total IQ score, $\mathrm{VCl}$ and PRI.

WISC-IV, Wechsler Intelligence Scale-IV.
80.1\%, HIP group: $80.7 \%$, non-HIP group: $79.5 \%$ ), and this high frequency, which reflects a problem of anxiety concerning most of the children recruited in the present study, might explain, because of a lack of discrimination of the sample, the absence of relationships observed between anxiety assessed by parents and total IQ scores or any of the four WISC-IV indices (VCI, PRI, WMI, PSI). In any case, our results underline the importance of using several different observational sources (parents, child and child psychiatrist evaluations) in order to assess more thoroughly anxiety behaviours, symptoms and disorders.

\section{Relationships between anxiety and verbal ability or perceptual reasoning}

Our study sheds light on the anxiety-related symptoms reported by children with high verbal potential $(\mathrm{VCI} \geq 130)$ compared with children with poorer verbal skills $(\mathrm{VCI}<130)$. This significant association concerned not just the overall anxiety score, but also the physiological anxiety and worry/oversensitivity subscales. To our knowledge, this is the first study that assesses specifically anxiety among children with high and without high verbal potential. Our findings raise the issue that children and adolescents who invest in the cognitive sphere of verbal skills, choosing their words with care, using a wide vocabulary and talking like grown-ups from a very early age, may display some specific psychological characteristics.

Given the literature, several hypotheses can be proposed. First, some authors argue that high intellectual functioning, and more particularly verbal overinvestment, should be regarded as a mechanism for coping with anxiety. ${ }^{19}$ Overinvestment in language may reflect a need and an attempt for control to avoid being invaded and overwhelmed by emotions that are, by their very nature, difficult to control. However, these attempts to control emotions through verbal language overinvestment seem to fail given that in this study high anxiety is associated with high VCI. Inversely, it can be argued that these children encounter anxiety-provoking difficulties precisely because of their exceptional verbal skills. They may suffer from a wider gap between their advanced verbal skills and their physical (weight and height), psychomotor and emotional development than children who are gifted in other spheres and may experience more acutely this dyssynchrony. ${ }^{20}$ These children may be able to express their goals quickly and from an early age, but then they find themselves unable to attain them because of their youth and immaturity in other areas of development.

Moreover, parents of children with high VCI may value and nurture their verbal and academic prowess to the detriment of other areas that might allow them to achieve greater self-fulfilment. When too much emphasis is placed on verbal skills, children may engage less in play and creativity, thus losing the notion of pleasure. This may then lead to excessive striving for top marks at school which, when associated with perfectionism and fear of failure, may generate performance anxiety.

In addition, children with high verbal skills may sometimes have problems with relationships, because these skills are more salient in social situations than mathematical or spatial abilities, ${ }^{21}$ and set them apart from their peers, potentially resulting in anxiety and rejection. ${ }^{22}$ Furthermore, high verbal potential reflected by a high VCI may be associated with high ability in verbal identification and expression of emotions, which can in turn increase awareness of emotions and lead to crystallisation with a reinforcement of these emotions. Therefore, expression of anxiety though verbal language might act not only as a mode of representation of anxiety but also as a reinforcement of anxiety contributing to higher anxiety scores on the self-report R-CMAS scale. 
These different explanations may interact: whereas verbal overinvestment may initially constitute a means of warding off anxiety, this adaptive and defensive mode of functioning may subsequently place the child in a difficult position and foster the emergence of anxiety disorders. Finally, it cannot be ruled out that children with high VCI are more able than children without high VCI to identify and express verbally their emotions through a self-report inventory that is based on verbal identification and expression of anxiety. In this case, high R-CMAS anxiety scores in children with high VCI would not mean that these children are more anxious than children without high VCI but would rather reflect a methodological bias of assessment. It would explain why this result of an association between anxiety and high verbal potential is found in the child's self-report evaluation but not in the parental or child psychiatric evaluation, highlighting the need for multiple observational sources.

Our study also revealed a significant association between high PRI functioning (PRI $\geq 130$ ) and anxiety reported on the R-CMAS. Children with high perceptual reasoning (PRI $\geq 130$ ) were statistically less anxious (total anxiety score and worry/oversensitivity subscore) than children without high perceptual reasoning (PRI $<130)$. No previous study described psychological features of a high PRI population. The PRI measures fluid, as opposed to crystallised intelligence, and reflects generally the ability to find new solutions to new problems. As such, it measures respondents' ability to use their senses to structure their thinking and organise themselves. Children who are highly skilled in this area probably prefer what are sometimes rather solitary problem-solving activities to verbal activities. They are less concerned with existential questioning or social preoccupations, both potential sources of anxiety. Also, high perceptual reasoning might be used as a resource by children to solve stressful problems and keep emotions at a distance through reasoning, which may explain, in both cases, low anxiety scores observed in high PRI children. This can be related to the idea developed by Alfred Korzybski ${ }^{23}$ that rational thinking with reasoning process can decrease the negative effects of emotional reactions. Finally, it can be hypothesised that lower levels of anxiety may allow children to develop and express, thanks to a calm and secure internal environment, their perceptual reasoning potential and lower anxiety levels could therefore contribute to high PRI scores observed in these children.

Our results suggest that it would be useful to focus on individual cognitive indices, especially given that heterogeneous WISC-IV profiles are more frequent than homogeneous profiles in the clinical population coming to the Center but also in a general population. ${ }^{25}$ The definition of HIP is a theoretical definition with a predetermined cut-off threshold (total IQ $\geq 130$ on the Wechsler scales according to the World Health Organization). Moreover, as the total IQ is a composite score, it can only be interpreted if it is based on broadly homogeneous indices to be representative of the child's intellectual capabilities. In the course of our clinical practice, we often come across children with no overall homogeneous intellectual potential, but rather a heterogeneous profile characterised by advanced skills in one or several domains. Most of these young individuals have high verbal skills (VCI scores considerably higher than the average score for children of their age). Verbal comprehension is a homogeneous index that measures crystallised intelligence. It is strongly linked to academic knowledge, and extremely sensitive to the learning opportunities available to children in their family environment; it is a reliable index, insofar as the examiner's subjectivity can have only a limited impact, given that the test is highly standardised. ${ }^{25}$ As well as being associated with anxiety, it is therefore highly predictive of learning and academic success. As such, we believe that the VCI is a useful measure for assessing children, as it has sound metric qualities and is of considerable clinical interest.
Several studies have indicated that the higher the total IQ, the greater the tendency for heterogeneous functioning and the weaker the correlations between the various subscales. ${ }^{26,27}$ It is important to bear in mind that cognitive tests are not particularly sensitive at the extremes, making it difficult to gain a reliable picture of individuals with a particularly high IQ (i.e. total IQ $\geq 150$ ). ${ }^{17}$ It is therefore legitimate to wonder whether the total IQ is a suitable measure for identifying HIP when it is used in isolation, without any other indices. Published in December 2016, the WISC-V is designed to improve profile accuracy precisely by adding new (ancillary) indices.

Based on our results, it appears that the VCI might be considered as a vulnerability factor for anxiety and PRI as a protective factor for anxiety (WMI and PSI indices were not significantly associated with anxiety scores). These opposing effects of two different aspects of intelligence might partly explain the discrepant relationships observed in the literature between intellectual functioning and anxiety; depending on the loading of the verbal component or reasoning component the results will differ. Furthermore, the directions of these effects can open interesting perspectives for further studies. It should also be noted, as indicated in the results section, that VCI and PRI scores are significantly and positively correlated. However, because these two dimensions of intelligence seem to have opposite effects on anxiety, they tend to nullify each other. This might explain why several studies using only a total IQ score did not find any effects of intelligence on anxiety assessed on selfreport questionnaires.

\section{Study limitations}

Some limitations of the study should be acknowledged. First, the parental assessments of children's anxiety disorders, collected over the phone, were purely observational. As with all instruments based on observation, they were therefore dependent upon the observers' subjectivity. Although we use the same standardised and systematic interview grid for every child who attends the Center for an assessment, this tool has not been validated in clinical research. It might, therefore, be useful to supplement parental assessments with a properly validated instrument such as the Child Behavior Checklist. It is noteworthy that subjectivity cannot be ruled out either from the child psychiatrist's or child's evaluation. All observational sources are subject to subjectivity and should be therefore multiple to limit this bias. Second, although our control group was composed of children without HIP, there was a recruitment bias, given that they had all attended the CNAHP because of psychological and/or academic problems. This was therefore an atypical population probably not representative of the general population between the ages of 6 and 16 years. Thus, it would be useful to compare children with HIP who have difficulties attending the CNAHP with a sample of 6- to 16-year-olds drawn from the general population.

\section{Implications}

Anxiety in children with HIP was found in our study to be a very frequent parental preoccupation (80.7\%) leading parents to bring their children to the CNAHP. Better understanding of the particularities and difficulties encountered by children with HIP, including anxiety, can improve their care and the development of their cognitive potential. Based on the results of this study, assessment of anxiety is highly recommended in children and adolescents with HIP who have school, behavioural and/or psychological difficulties. Early identification of anxiety disorders in this population can improve clinical practice by providing necessary therapeutic care.

This study highlights the importance of different observational sources of assessment. Indeed, children with high overall intellectual functioning (total $I Q \geq 130$ ) who were referred to the CNAHP 
showed significantly more anxiety disorders than children without high overall intellectual functioning (total IQ $<130$ ) according to the child psychiatric diagnosis but not according to the parental observation or the child's self-evaluation. However, based on the child's self-evaluation, children with high verbal potential $(\mathrm{VCI} \geq 130)$ perceived themselves as being significantly more anxious than those without high verbal potential $(\mathrm{VCI}<130)$, whereas children with high perceptual reasoning potential $(P R I \geq 130)$ perceived themselves as being significantly less anxious than those without high perceptual reasoning potential (PRI <130). These findings show the importance of studying different dimensions of cognitive functioning (such as the VCI and PRI), instead of focusing only on overall intellectual functioning (total IQ score). They offer interesting perspectives on children with HIP, based on their cognitive profile and regardless of their total IQ score, given that high verbal potential appears to be, in the present study, a factor of vulnerability for anxiety and that high perceptual reasoning potential may be a protective factor. Future research is needed to understand better the relationships between high intellectual functioning and anxiety, and their consequences for intellectual potential and talent development.

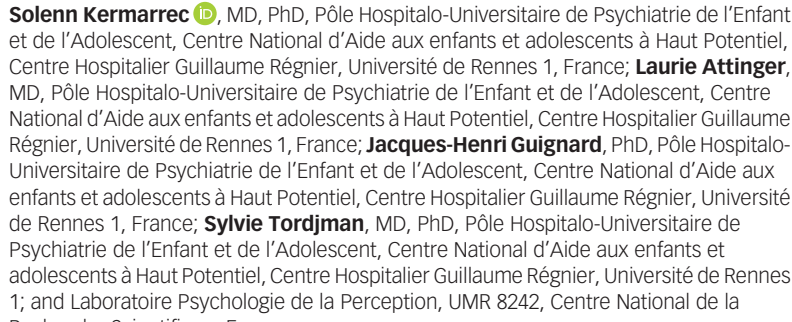

Solenn Kermarrec (D), MD, PhD, Pôle Hospitalo-Universitaire de Psychiatrie de l'Enfant et de l'Adolescent Centre National d'Aide aux enfants et adolescents à Haut Potentiel, Centre Hospitalier Guillaume Régnier, Université de Rennes 1, France; Laurie Attinger MD, Pôle Hospitalo-Universitaire de Psychiatrie de I'Enfant et de I'Adolescent, Centre National d'Aide aux enfants et adolescents à Haut Potentiel, Centre Hospitalier Guillaume Régnier, Université de Rennes 1, France; Jacques-Henri Guignard, PhD, Pôle HospitaloUniversitaire de Psychiatrie de l'Enfant et de l'Adolescent, Centre National d'Aide aux enfants et adolescents à Haut Potentiel, Centre Hospitalier Guillaume Régnier, Universite de Rennes 1, France; Sylvie Tordjman, MD, PhD, Pôle Hospitalo-Universitaire de Psychiatrie de l'Enfant et de l'Adolescent, Centre National d'Aide aux enfants et adolescents à Haut Potentiel, Centre Hospitalier Guillaume Régnier, Université de Rennes 1; and Laboratoire Psychologie de la Perception, UMR 8242, Centre National de la Recherche Scientifique, France

Correspondence: Solenn Kermarrec. Email: s.kermarrec@ch-guillaumeregnier.fr

First received 3 Sep 2019, final revision 3 Dec 2019, accepted 21 Dec 2019

\section{Funding}

This study was funded by the CHGR (Centre Hospitalier Guillaume Régnier).

\section{Acknowledgements}

We thank the secretary, Cindy Menguy, who conducted the parental semi-structured phone interview and the psychologists of the CNAHP who participated in the cognitive assessments: Lisa Allain, Laura Blondel, Hélène Hardy, Marjo Lobach and Emilie Moguen.

\section{Data availability}

The structure of the data-set and the coding specification are available from the authors on request.

\section{Author contributions} S.K., L.A. and S.T. conceived and designed the study. S.K. and S.T. recruited the children and
evaluated anxiety. L.A., S.K., J.H.G. and S.T. performed the data analysis. S.K., L.A. and S.T. evaluated anxiety. L.A., S.K., J.H.G. and S.T. performed the data analysis. S.K., L.A. and S.T.
wrote the first draft of the manuscript, and all authors commented on the manuscript and revised the article.

\section{Declaration of interest}

None

ICMJE forms are in the supplementary material, available online at https://doi.org/10.1192/ bjo.2019.104.

\section{References}

1 World Health Organization. The ICD-10 Classification of Mental and Behavioural Disorders: Diagnostic Criteria for Research. World Health Organization, 1993.
2 American Psychiatric Association. Diagnostic and statistical manual of mental disorders (5th edn) (DSM-5). American Psychiatric Publishing, 2013.

3 Guignard $\mathrm{JH}$, Kermarrec S, Tordjman S. Relationships between intelligence and creativity in gifted and non-gifted children. Learn Individ Differ 2016; 52: 209-15.

4 Roberts SM, Lovett SB. Examining the " $F$ " in gifted: academically gifted adolescents' physiological and affective responses to scholastic failure. J Educ Gifted 1994; 17: 241-59.

5 Peyre H, Ramus F, Melchior M, Forhan A, Heude B, Gauvrit N. Emotional, behavioral and social difficulties among high-IQ children during the preschool period: results of the EDEN mother-child cohort. Pers Indiv Differ 2016; 94: 366-71.

6 Guénolé F, Louis J, Creveuil C, Baleyte JM, Montlahuc C, Fourneret P, et al.. Behavioral profiles clinically referred children with intellectual giftedness. Biomed Res Int 2013; 2013: 540153.

7 Rost DH, Czeschlik T. The psycho-social adjustment of gifted children in middlechildhood. Eur J Psychol Educ 1994; 9: 15-25.

8 Forsyth P. A Study of Self-concept, anxiety, and security of children in gifted French immersion, and regular classes. Rev Can Counsel 1987; 21: 153-56.

9 Terman LM. Genetic studies of genius ...: Mental and Physical Traits of a Thousand Gifted Children. Stanford University Press, 1925

10 Scholwinsky E, Reynolds CR. Dimensions of Anxiety among high IQ children. Gifted Child Quart 1985; 29: 125-30.

11 Reynolds CR, Bradley M. Emotional stability of intellectually superior children versus nongifted peers as estimated by chronic anxiety levels. School Psychol Rev 1983; 12: 190-4.

12 Fouladchang $M$, Kohgard A, Salah V. A study of psychological health among students of gifted and nongifted high schools. Procd Soc Behv 2010; 5: 1220-25.

13 Zeidner M, Shani-Zinovich I. Do academically gifted and nongifted students differ on the big-five and adaptive status? Some recent data and conclusions. Pers Indiv Differ 2011; 51: 566-70.

14 Martin LT, Burns RM, Schonlau M. Mental disorders among gifted and nongifted youth: a selected review of the epidemiologic literature. Gifted Child Quarter 2010; 54: 31-41.

15 Tong J, Yewchuk C. Self-concept and sex-role orientation in gifted high school students. Gifted Child Quarter 1996; 40: 15-23.

16 Simoes Loureiro I, Loventhal F, Lefevre L, Vaivre-Douret L. Étude des caractéristiques psychologiques et psychobiologiques des enfants à haut potentiel. [Study of the psychological and psychobiological characteristics of high potential children.] Enfance 2010; 62: 27-44.

17 Wechsler D. Echelle d'intelligence de Wechsler pour enfants WISC IV. IChildren's Wechsler Intelligence Scale WISC-IV.] Ed. du Centre de Psychologie Appliquée, 2005.

18 Reynolds C, Richmond B. R-CMAS Revised Children's Manifest Anxiety Scale: Echelle d'Anxiété Manifeste pour Enfants-Révisée. Les Editions du Centre de Psychologie Appliquée, 1999.

19 Weismann-Arcache C. Hétérogénéité ou dysharmonie ? Clinique du fonctionnement mental des enfants à haut potentiel. [Heterogeneity or disharmony? High potential children's mental functioning clinic.] Bull Psychol 2006; 485: 481-9.

20 Terrassier JC. Les enfants Surdoués ou la Précocité Embarrassante (4eme éd). [Gifted children or embarrassing precocity.] ESF Groupe Elsevier, 2009.

21 Dauber SL, Benbow CP. Aspects of personality and peer relations of extremely talented adolescents. Gifted Child Quarter 1990; 34: 10-4.

22 Rousseau JJ, Coulet H. Narcisse ou L'amant de Lui-Même. INarcissus or lover of himself.] Les Editions Desjonquères, 2008.

23 Korzybski A. Science and Sanity: An Introduction to Non-Aristotelian Systems and General Semantics (5th edn). Institute of General Semantics, 1994.

24 Ackerman PL, Heggestad ED. Intelligence, personality, and interests: evidence for overlapping traits. Psychol Bull 1997; 121: 219-45.

25 Grégoire J. L'examen Clinique de L'intelligence de L'enfant: Fondements et Pratique du WISC-IV. [Clinical examination of child intelligence: foundations and practise of WISC-IV.] Editions Mardaga, 1999.

26 Detterman DK, Daniel MH. Correlations of mental tests with each other and with cognitive variables are highest for low IQ groups. Intelligence 1989; 13: $349-59$

27 Lynn R. Does Spearman's g decline at high IQ levels? Some evidence from Scotland. J Genet Psychol 1992; 153: 229-30. 